\title{
Multistate projections of Australia's Indigenous population: interacting area group and identification status change
}

\author{
James Raymer, Yanlin Shi, James O'Donnell, and Nicholas Biddle*
}

\begin{abstract}
In this paper, we develop a multistate projection model that allows the Australian Aboriginal and Torres Strait Islander (Indigenous) population to move between area classifications and Indigenous self-identification statuses. We combine data from the Australian Census Longitudinal Dataset and the 2011 census to estimate the transitions between 2006 and 2011. This information is then included in a multistate population projection model to illustrate the effects of migration and identification change over time in relation to natural increase (i.e., births-deaths). The results show how patterns of identification change differ by both age and type of migration, and how migration and identification change affect patterns of Indigenous population change across major cities, regional areas, and remote areas in Australia.
\end{abstract}

\section{Introduction}

The Aboriginal and Torres Strait Islander Australian population is made up of the self-identified descendants of the original inhabitants of the Australian continent and adjacent islands. Hereafter referred to as Indigenous Australians, this population has not only been growing rapidly due to natural population increase, but has been growing faster than the demographic components of fertility, mortality, and

\footnotetext{
* James Raymer (corresponding author), School of Demography, Research School of Social Sciences, Australian National University, 9 Fellows Road, Acton ACT 2601, Australia

Email: james.raymer@anu.edu.au

Yanlin Shi, Department of Actuarial Studies and Business Analytics, Macquarie University, Australia James O'Donnell, School of Demography, Research School of Social Sciences, Australian National University, Australia

Nicholas Biddle, Centre for Aboriginal Economic Policy Research and ANU Centre for Social Research and Methods, Research School of Social Sciences, Australian National University, Australia
} 
migration can explain. While intercensal growth rates have varied, these trends been consistent features of the development of the population since it was first enumerated for all of Australia by the Australian Bureau of Statistics (ABS) in the 1971 census (Biddle and Wilson 2013). The non-demographic components of Indigenous population change are thought to be attributable to better enumeration practices and net increases in self-identification (ABS 2013b; O'Donnell and Raymer 2015). Not surprisingly, traditional demographic estimation and projections of Indigenous populations in Australia have been greatly hindered by these additional factors.

Understanding the drivers of Indigenous population change in Australia is important for many reasons. The Indigenous population has a unique and vibrant culture going back at least 40,000 years (Taylor 1997, 2003), with some evidence suggesting that the population underwent genetic divergence up to 72,000 years ago (Malaspinas et al. 2016). However, the Indigenous population is socioeconomically disadvantaged in comparison to the majority European-ancestry population (Steering Committee for the Review of Government Service Provision 2014) and most of the many migrant populations from around the world who have settled in Australia. Moreover, the demographic behaviours of the Indigenous people are known to differ from those of other population groups in Australia: e.g., their levels of fertility and mortality are higher, and their internal migration patterns are distinct (Biddle and Crawford 2015; Raymer et al. 2017). The causes of these demographic and socioeconomic differences are complex, but include Indigenous people's relative geographic isolation from the rest of the Australian population, their relatively poor access to services, the lingering effects of previous incidences of conflict and dispossession, and ongoing policy failures (Biddle et al. 2015). Understanding these issues is essential for planning and developing national- and local-level policies aimed at improving the conditions of the Indigenous population.

Our aims in this paper are to gain an understanding of the relationships between migration and identification change, and to develop a projection tool that can show the long-term effects of these factors on population change. To capture the dynamics and complexity of Indigenous population change, we utilise data on Indigenous and non-Indigenous births, deaths, and internal migration; and on identification change by age, sex and residence type. The identification and migration probabilities are obtained from the sample-based Australian Census Longitudinal Dataset (ACLD) representing the 2006-2011 period. We then enter the demographic and identification information into a multistate population projection model in order to explore the long-term consequences of migration and identification change.

The paper is structured as follows. In Section 2, we provide background on the Indigenous population and patterns of identification change in Australia. In Section 3, we describe the data, the multistate projection model, and the transition estimation methods. In Section 4, we present the results, focusing on the analysis of the interaction between identification change and migration and the multistate projections. The paper ends with a discussion and a conclusion. 


\section{Background}

The Australian Indigenous population is unique in many ways, including in terms of its growth and spatial distribution patterns. Whereas just 115,000 people identified as Aboriginal ${ }^{1}$ in the 1971 census (ABS 1971), the total Indigenous population count had grown to 548,000 by the 2011 census (ABS 2012). This implies an average annual growth rate of 4.0 per cent, which outstrips the average 1.3 per cent growth rate of the total Australian population over the same period (ABS 2014a). This rate is particularly impressive considering that the non-Indigenous population benefited from international migration, with the most recent (2011) census indicating that 27 per cent of the total population were born abroad.

In 1986, the ABS first began to apply post-enumeration estimates to Indigenous census counts. At that time, the resident Indigenous population was estimated at 240,000 people (ABS 2014a). By 2011, this figure had increased to 670,000 (ABS 2013a), reflecting an even higher average growth rate of 4.2 per cent per year. While these estimates partly reflect changes in post-enumeration methodologies and an expansion of the Post Enumeration Survey (PES) to remote areas, it is clear that the Indigenous population has been growing at a much faster rate than the rest of the population.

Demographers and other researchers have pointed out that in most intercensal periods, these estimated levels of growth have been higher than the demographic components of births, deaths, and marriages allow (Biddle and Wilson 2013; Gray 1997; Kinfu and Taylor 2005; O’Donnell and Raymer 2015; Ross 1996) Various explanations have been put forward for this otherwise unexplained growth trend, including improvements in enumeration practices, inter-partnering between Indigenous and non-Indigenous Australians, and an increasing tendency among Australians to identify as Indigenous (Gray 1997; O’Reilly 1994; Ross 1996). Until recently, however, there has been little direct evidence of the respective contributions of each of these factors to Indigenous population growth.

The 2006 to 2011 intercensal period was marked by particularly strong growth. In 2006, the ABS estimated that there were around 517,000 Indigenous Australians living in Australia, representing about 2.5 per cent of the overall population (ABS 2013a). By 2011, this share had increased to approximately 3.0 per cent of the total Australian population. The ABS (2013b) attributed 43 per cent of this growth to natural increase and 36 per cent to improved enumeration practices, leaving a further 21 per cent unexplained. Moreover, with the publication of the ACLD, the period marked the first time data became available that could be used to explore some of this unexplained growth (ABS 2013b). The ACLD is explained in more detail below, but in short it links a five per cent sample of census records from the 2006 to the 2011 census, which allows users to cross-tabulate identification status in 2006 by identification status in 2011.

\footnotetext{
1 Note that Torres Strait Islanders were added as an additional category in subsequent collections.
} 
Raymer et al. (2017) attributed the rapid increase in the Indigenous population between 2006 and 2011 to:

(1) the relatively large share of the population of childbearing ages;

(2) higher fertility rates;

(3) high partnering rates in urban areas between Indigenous males and nonIndigenous females that resulted in additional children being identified as Indigenous;

(4) better enumeration by the ABS; and

(5) identification change.

The ACLD data show that some Australians changed how they identify and how they were identified between the 2006 and 2011 censuses. Of the 775,000 sample respondents who identified as non-Indigenous in 2006, an estimated 1700 identified as Indigenous in 2011 ( 0.2 per cent). Over the same period, 1400 respondents changed how they identified from Indigenous to non-Indigenous (9.2 per cent) (ABS 2013b). Thus, while identification change evidently operates in both directions, it appears that over the study period it had a positive net impact on Indigenous population growth.

Applying population weights to the sample estimate (that take into account both the sampling strategy and differences in linkage rates) produces a net positive contribution of 21,000 people due to identification change. In their analysis of age and sex patterns, O'Donnell and Raymer (2015) found that a large proportion of identification changes occur in early childhood, with the probabilities of change in both directions peaking at ages 5-9. The results of the analysis by Biddle and Crawford (2015) suggest that identification is also associated with geographic location, as the change probabilities were shown to vary depending on whether the respondents lived in a major city, a regional area, or a remote area. Most importantly from the point of view of this paper, they found that geographic mobility between 2001 and 2006 predicted identification change patterns between 2006 and 2011.

The relationship between geography and identification change is particularly pertinent given how the Indigenous population is geographically distributed. As we describe below, the Indigenous population is more dispersed than the nonIndigenous population. While there are urban clusters of the Indigenous population in many Australian cities and regional towns, Indigenous individuals and families are also dispersed throughout the non-Indigenous population, and there are discrete Indigenous communities scattered across regional and remote areas.

Given the large landmass covered by regional and remote Australia, Biddle and Wilson (2013) pointed out that despite being relatively small in size, the Indigenous population have responsibility for, and stewardship over, most of the Australian continent. Regional and remote Indigenous communities are, however, under constant pressure from a range of challenges, including high rates of ruralurban migration; socioeconomic disadvantage and a lack of opportunities for young people; community dysfunction; volatile government policy; and the difficulties of remote service delivery, particularly in the areas of housing, health, education, and 
municipal services. While these challenges are not experienced to the same degree in larger towns and cities, urban Indigenous populations nevertheless experience higher levels of socioeconomic disadvantage than their non-Indigenous neighbours; as well as higher rates of discrimination (Biddle et al. 2013) and lower rates of subjective wellbeing (Biddle 2014) than their remote counterparts. Understanding the size, growth, and distribution of the Indigenous population is therefore of farreaching importance.

Indeed, future patterns of inhabitation of inland Australia and their implications for land use, planning, and service delivery - as well as efforts to reduce economic inequality in Australia - depend to a great extent on the development of the Indigenous population. The proliferation of Indigenous population projections over the last 25 years attests to the importance of this topic (ABS 2004, 2009, 2014b; Biddle 2013; Biddle and Taylor 2009; Gray 1997b; Gray and Gaminiratne 1993; Khalidi, 2008; O'Donnell and Raymer 2015; Wilson 2009, 2014). But due to a lack of data, the twin issues of regional-remote-urban migration and identification change have rarely been appropriately addressed, and never in combination. In official and academic projections, it is typically assumed out of necessity that populations are closed to identification change (Wilson 2009). Similarly, in projections of interregional migration, it is usually assumed that net migration levels remain constant (e.g., ABS 2004, 2009, 2014b) - even though this approach is blind to the dynamic interactions between origin and destination populations.

Recent advances in thinking, data, and methods have created new possibilities for studying developments in the Indigenous population; most notably, opportunities to model the population within a multistate (or a multiregional) demographic framework (Wilson 2009; Biddle and Wilson 2013; O'Donnell and Raymer 2015). To demonstrate the potential effects of identification change on long-term Indigenous population growth, O'Donnell and Raymer (2015) constructed synthetic Indigenous and non-Indigenous populations and allowed them to interact through identification change probabilities calculated from the ACLD. The findings of this model suggest that identification change is most common in the relatively heavily populated and urbanised state of New South Wales (where observed rates of identification change are high), and is less common in the relatively regional and remote Northern Territory (where identification change is low). As these projections were closed to interregional migration, an important extension to this work lies in incorporating both identification change and interregional (or area group) migration into a similar multistate projection model. 


\section{Data and methods}

\subsection{Available data}

The 2011 census population counts can be decomposed by sex, age, current residence, residence five years ago, and current identification status. In addition, the ACLD links a sample of the 2006 and 2011 censuses.

The ACLD was released by the ABS in late 2013, and 'a sample of almost one million records from the 2006 Census (wave 1) was brought together with corresponding records from the 2011 Census (wave 2) to form the largest longitudinal dataset in Australia' (ABS 2013c). To produce the ACLD, five per cent of records from the 2006 census were linked probabilistically with available data from the 2011 census based on the most likely match, given observed characteristics. Because this linking was done without knowing the individual's exact name and address, an unobserved minority of linked pairs are not of the same individual. We use data from the ACLD to calculate the age-specific probabilities of identification change between the two census periods.

Mortality data are sourced from the 2010-12 Indigenous life tables (ABS 2013d), while fertility rates are sourced from vital registration data compiled in the ABS (2015) Births publication. Net international migration data for the 2006-2011 period for the non-Indigenous population data were obtained from the Australian Bureau of Statistics, and represent the difference between immigration and emigration. International migration is measured using registration (passenger card) data. An immigrant (emigrant) is defined as a person who has entered and remained in (left and remained outside of) Australia for 12 out of 16 months. Finally, for the projections, the 2011 Estimated Resident Population is used as the starting point.

The population counts of the 2011 census by usual residence in $2006(t)$, usual residence in $2011(t+5)$, and identification status in 2011 are presented in Table $1 .^{2}$ The major city, regional area, and remote area definitions are taken from the ABS (2013b). Collectively, they comprise a geographic area classification known as ASGS-RA, which reflects the relative proximity of every location in Australia to towns and cities. The classification is created by constructing a one-kilometre grid for all of Australia and assigning an index value, known as the Accessibility or Remoteness Index of Australia (ARIA+), to each square in the grid based on the average road distance from the square to the nearest town or urban centre of various population sizes. The grid is laid on top of the Statistical Area 1 (SA1) geographic structure to produce an ARIA+ score for each SA1. SA1s with an ARIA+ score of 0.0 to 0.2 are classified as major cities; of 0.2 to 5.9 , as regional areas; and of greater than 5.9, as remote areas. These area classifications are presented for Australia in

\footnotetext{
2 Three important components of the population are excluded from these counts: those who were under five years old in 2011, those who did not state their identification status, and those who did not state their location of usual residence in either 2006 or 2011.
} 


\section{Figure 1:}

Map of Major Cities, Regional Areas, and Remote Areas in Australia

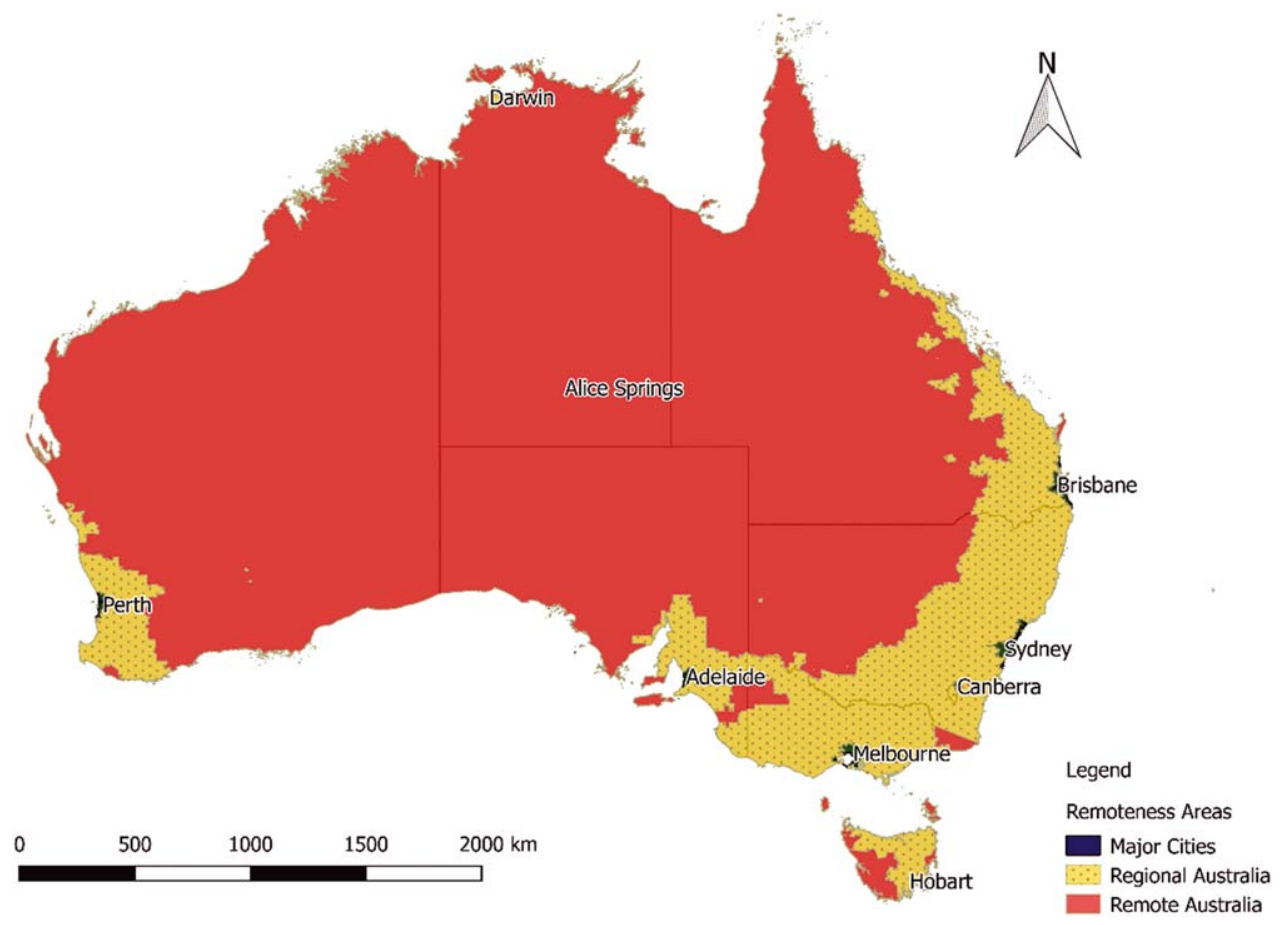

Figure 1. For example, an SA1 that lies within an urban area with a population greater than 250,000 or within one-fifth of the average distance to such a centre is classified as major city. An SA1 that is 0.5 times the average distance to a major city, 1.2 times the average distance to a town with between 48,000 and 250,000 people, and sits inside a town with between 18,000 and 48,000 people obtains an ARIA+ score of $1.7(0.5+1.2+0.0)$, and is classified as a regional area $(0.2<1.7 \leq 5.9)$. Meanwhile, remote areas are farthest from major urban centres. More information on how ARIA+ is calculated is available from the Hugo Centre for Migration and Population Research at the University of Adelaide. ${ }^{3}$

Table 1 shows that of the total Indigenous population in 2011, 185,000 (43 per cent) lived in regional areas, 150,000 (35 per cent) lived in major cities, and 95,000 (22 per cent) lived in remote areas. In contrast, of the total non-Indigenous population in 2011, 11.8 million (70 per cent) lived in major cities, while only 277,000 ( 2 per cent) lived in remote areas. The shares of the populations living in

\footnotetext{
3 https://www.adelaide.edu.au/apmrc/research/projects/category/about_aria.html.
} 
Table 1:

Inter-area group migration by identification status, 2006-2011

\begin{tabular}{lrrrr}
\hline \multicolumn{5}{c}{ Destination } \\
\cline { 2 - 5 } Origin & MC & RG & RM & Total \\
\hline \multicolumn{4}{l}{ A. Indigenous } \\
MC & 137,109 & 9,133 & 1,093 & 147,335 \\
RG & 10,434 & 168,782 & 3,746 & 182,962 \\
RM & 2,142 & 7,332 & 89,717 & 99,191 \\
Total & 149,685 & 185,247 & 94,556 & 429,488 \\
B. Non-Indigenous & & & \\
MC & $11,332,633$ & 445,045 & 35,239 & $11,812,917$ \\
RG & 390,835 & $4,280,232$ & 41,505 & $4,712,572$ \\
RM & 30,990 & 53,220 & 201,066 & 285,276 \\
Total & $11,754,458$ & $4,778,497$ & 277,810 & $16,810,765$ \\
\hline \multicolumn{5}{r}{} \\
\hline
\end{tabular}

Note: $\mathrm{MC}=$ Major Cities; $\mathrm{RG}=$ Regional Areas; $\mathrm{RM}=$ Remote Areas . Source: 2011 Census.

these area groups did not change much between 2006 and 2011, but the population numbers grew by 11.9 per cent in major cities, 12.6 per cent in regional areas, and 8.2 per cent in remote areas.

Looking at the data on inter-area group migration in Table 1, we see some notable differences between the Indigenous and non-Indigenous populations. First, the Indigenous people living in major cities were more likely to move to a regional area or remote area (i.e., $9,133+1,093 / 147,335=7$ per cent) than the non-Indigenous (i.e., $445,045+35,239 / 11,812,917=4$ per cent). The opposite was the case for those living in regional and remote areas, where the Indigenous population had lower out-migration propensities than the non-Indigenous population. For example, almost 30 per cent of the non-Indigenous population but only 10 per cent of the Indigenous population living in remote areas moved to a major city or regional area between 2006 and 2011. Both populations exhibited higher propensities to move to regional areas when leaving major cities or remote areas. When moving from regional areas, both groups preferred to move to major cities.

\subsection{Projection framework}

The following multistate demographic accounting model (Rogers 1995) is employed to project the Indigenous and non-Indigenous populations of Australia.

$$
\mathbf{K}^{(t+5)}=\mathbf{G K}^{(t+5)}+\mathbf{I}
$$


where

$$
\mathbf{K}^{(t)}=\left[\begin{array}{c}
\mathbf{K}_{0}^{(t)} \\
\mathbf{K}_{5}^{(t)} \\
\vdots \\
\mathbf{K}_{75+}^{(t)}
\end{array}\right], \quad \mathbf{K}_{x}^{(t)}=\left[\begin{array}{c}
K_{11 x}^{(t)} \\
K_{12 x}^{(t)} \\
\vdots \\
K_{23 x}^{(t)}
\end{array}\right], \quad \mathbf{I}_{x}=\left[\begin{array}{c}
I_{11 x}^{t, t+5} \\
I_{12 x}^{t, t+5} \\
\vdots \\
I_{23 x}^{t, t+5}
\end{array}\right],
$$

and

$$
\mathbf{G}=\left[\begin{array}{ccccccccc}
0 & 0 & 0 & \mathbf{B}_{10} & \cdots & \mathbf{B}_{45} & 0 & \cdots & 0 \\
\mathbf{S}_{0} & & & & \ddots & & & & \\
0 & \mathbf{S}_{5} & & \ddots & & & \vdots \\
\vdots & \vdots & & \ddots & & & \\
0 & 0 & & \cdots & & & & \mathbf{S}_{70} & 0
\end{array}\right] .
$$

$K_{\text {iax }}^{(t)}$ is the population at time $t$ by identification status $i(1=$ Indigenous, $2=$ nonIndigenous), by area group $a(1=$ major cities, $2=$ regional areas, $3=$ remote areas), and by age group $x(0-4,5-9, \ldots, 75+) . I_{\text {iax }}$ reflects the corresponding net immigration totals between the two time points. As specified in Rogers (1995), $\mathbf{S}_{x}$ and $\mathbf{B}_{x}$ are six-by-six matrices that are composed of the survival probability of moving from identification status $i$ and area group $a$ to identification status $j$ and area group $b$; and the survival fertility rate of women in identification status $i$ and area group $a$ contributing births to women in identification status $j$ and area group $b$, respectively. The projection is performed separately for males and females. The six subpopulations are defined as Indigenous major cities $\left(K_{11}\right)$, Indigenous regional areas $\left(K_{12}\right)$, Indigenous remote areas $\left(K_{13}\right)$, non-Indigenous major cities $\left(K_{21}\right)$, nonIndigenous regional areas $\left(K_{22}\right)$, and non-Indigenous remote areas $\left(K_{23}\right)$.

In our model framework, births are produced by females. In the construction of the fertility rates, we assume that women can give birth to both Indigenous and nonIndigenous babies. Non-Indigenous women give birth to Indigenous children largely by partnering with Indigenous men (Biddle and Johnstone 2014); whereas a much smaller percentage of Indigenous women give birth to non-Indigenous children While this pattern may seem counter-intuitive, it likely reflects personal factors that influence how people identify themselves and their children.

In this paper, we extend the multistate population projection of O'Donnell and Raymer (2015), which included age-specific transitions between Indigenous and non-Indigenous identification, by including transitions between residence area groups. Many standard cohort-component population projections models ignore transitions between states of residence, and instead rely on net migration or the slightly more detailed out-migration and in-migration rates. The problem with net migration and in-migration rates is that they include the incorrect population at risk of migrating in the denominator, which can seriously bias the projection results 
(Rogers 1990, 2015). The same is true for other life course transitions in which populations can move in both directions; e.g., ethnic self-identification, marriage, health, and employment.

\subsection{Indirect estimation}

In order to account for the identification status transition and migration among area groups simultaneously, we need to estimate the rates $\mathbf{S}_{x}$ described in Equation 1. Although such information can be extracted from the ACLD directly, the quality of this approach is questionable. For one thing, the ACLD only accounts for five per cent of the total Australian population data. Thus, after the decomposition, many of the numbers in the cells of the above matrix are small or zero, especially when disaggregated by age and sex. Furthermore, small counts have been randomized by the ABS to protect individual confidentiality. Therefore, we propose combining the ACLD data with the 2011 census data to produce more reliable inputs for analysis and use in a multistate population projection.

\subsubsection{Identification status transition and migration probabilities}

The process used to estimate the age- and sex-specific probabilities of inter-area group migration and identification change is described in this subsection. This process involves smoothing the ACLD data and combining them with the full census data.

To smooth the randomness in the ACLD transition data, we use the log-linear model, following Rogers et al. (2010). Consider, for example, the following main effects log-linear model:

$$
\ln \left(\hat{n}_{i a j b x y}\right)=I_{i}+O_{a}+J_{j}+D_{b}+A_{x}+S_{y}
$$

where $\hat{n}_{\text {iajbxy }}$ is the estimated table of transitions between area groups and identification status by age and sex. $I$ denotes identification status in 2006, $O$ denotes area group in 2006, $J$ denotes identification status in 2011, $D$ denotes area group in 2011, $A$ denotes age group, and $S$ denotes sex. The subscripts denote the categories in each variable. To choose the log-linear model for smoothing the data, we considered all two-way interactions of the above six factors and used the Akaike Information Criterion (AIC) ${ }^{4}$ goodness-of-fit measure, which has a penalty for the number of parameters in the model. Furthermore, we separately modelled the people who changed their identification status and those who did not change their status. This was done to preserve the full census migration flow data among Indigenous

$4 \quad A I C=2 k-2 \log (L)$, where $k$ is the number of parameters and $L$ is the fitted likelihood. Hence, AIC balances the model fitness (higher $L$ ) and parsimony (lower $k$ ). The model with a smaller AIC is preferred. 
and non-Indigenous populations, and to prevent the patterns of people who did not change their identification (i.e., the vast majority) from dominating the estimation of those who did.

The final model selected for those who did not change their identification contained the following two-way interaction terms in addition to all the main effect terms: $I O_{i a}, I D_{i b}, I A_{i x}, I S_{i y}, O D_{a b}, O A_{a x}, O S_{a y}, D A_{b x}, D S_{b y}$, and $A S_{x y}$. The final model selected for those who changed their identification status was $I A_{i x}, O D_{a b}$, $O A_{a x}, O S_{a y}$, and $D S_{b y}$. Note that identification change was treated separately in these models to prevent the patterns of people who did not change their identification from dominating the estimated patterns of those who did. Thus, because the patterns were treated separately, the variable of $J$ (identification status in 2011) and all related interactions were not needed or were redundant.

From the smoothed ACLD data, we can calculate $\hat{r}_{i a j b x y}$, which is the ratio of $\hat{n}_{i a j b x y}$ to $\hat{n}_{i j b x y}$, which can be used to augment the full census data. Therefore, the estimated full census table of transitions is obtained by $\hat{n}_{i a j b x y}^{c}=\hat{r}_{i a j b x y} n_{i j b x y}^{c}$, where $n_{i j b x y}^{c}$ is the directly available data from the 2011 census (without 2006 identification status).

Hence, the age- and sex-specific migration probabilities can be calculated as $\hat{s}_{i a j b x y}=\hat{n}_{\text {iajbxy }}^{c} / \hat{n}_{\text {iaxy }}^{c}$ where $\hat{n}_{\text {iaxy }}^{c}=\sum_{j, b=1}^{6} \hat{n}_{\text {iajbxy }}^{c}$ and $\hat{n}_{\text {iajbxy }}^{c}$ are the estimated census counts, reconstructed according to the new definitions of origins and destinations. In order to further smooth these probabilities across age groups, we employ the local polynomial regression (LOESS) methods to estimate age-specific probabilities, $\hat{s}_{i a j b x y}$, plotted in Figures 2 to 5 . Note that as there were only minor differences in the sex patterns, they are not presented in this paper.

The estimated age-specific probabilities of inter-area group migration for the Indigenous population are presented in Figure 2. Here, we see that the probabilities of staying in major cities (upper-left figure) remained at the same level (around 90 per cent) for most of the age groups, except for those aged 15 or younger and those aged 60 or older. For those staying in regional areas (centre figure) and remote areas (lower-left figure), there were relatively low probabilities in the childhood years (80-90 per cent), with steady increases thereafter. For the migration probabilities presented in the off-diagonal figures, the patterns were roughly similar; i.e., increasing until reaching the modal class (ranging between 10 and 20 years old) and then consistently decreasing. For the Indigenous population, the probabilities of migrating from major cities to regional areas and remote areas and from regional areas to remote areas were declining in early childhood, but then started increasing at around age 10 until reaching the modal class.

The estimated age-specific probabilities of inter-area group migration for the nonIndigenous population are presented in Figure 3 . These probabilities were roughly similar to those exhibited by the Indigenous population, although the magnitudes were quite different. It is worth noting that for non-Indigenous migration from major cities to regional areas, there was a noticeable pre-retirement peak at around age 55, which is not observed in the other cases. The probabilities of remaining in remote 
Figure 2:

Estimated age-specific probabilities of inter-area group migration for the Indigenous population, 2006-2011
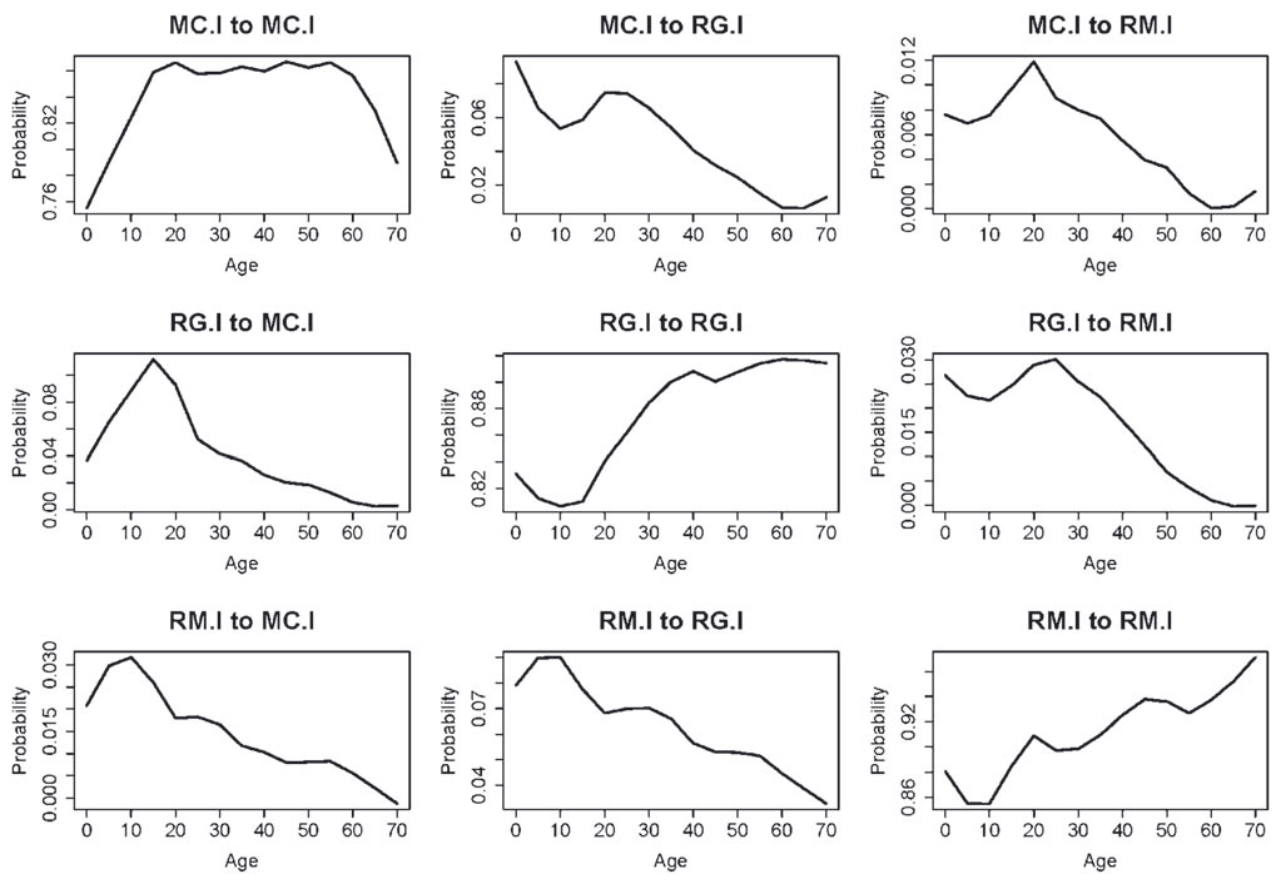

areas (lower-left figure) were also much lower than the probabilities of remaining in major cities and regional areas.

The estimated age-specific probabilities of inter-area group migration for the non-Indigenous population who changed their identification to Indigenous are presented in Figure 4. The corresponding probabilities for the Indigenous people who changed their identification to non-Indigenous are presented in Figure 5. In both figures, we find similar patterns, albeit with very different magnitudes. For instance, all population groups had higher probabilities in the childhood years, and most had low or decreasing trends with increasing age. The exceptions are the probabilities associated with living in remote areas at the beginning of the time interval (bottom panels), where there appear to be labour force peaks. We also see that those who changed their identification but remained in major cities and regional areas exhibited increasing age-specific probabilities after age 20. Finally, using the smoothed probabilities presented in Figures 2 to 5, we regenerate the census counts via $\tilde{n}_{\text {iajbxy }}^{c}=\hat{n}_{\text {iaxy }}^{c} \tilde{s}_{\text {iajbxy }}$, where the tilde symbol denotes the corresponding smoothed values. 
Figure 3:

Estimated age-specific probabilities of inter-area group migration for the non-Indigenous population, 2006-2011
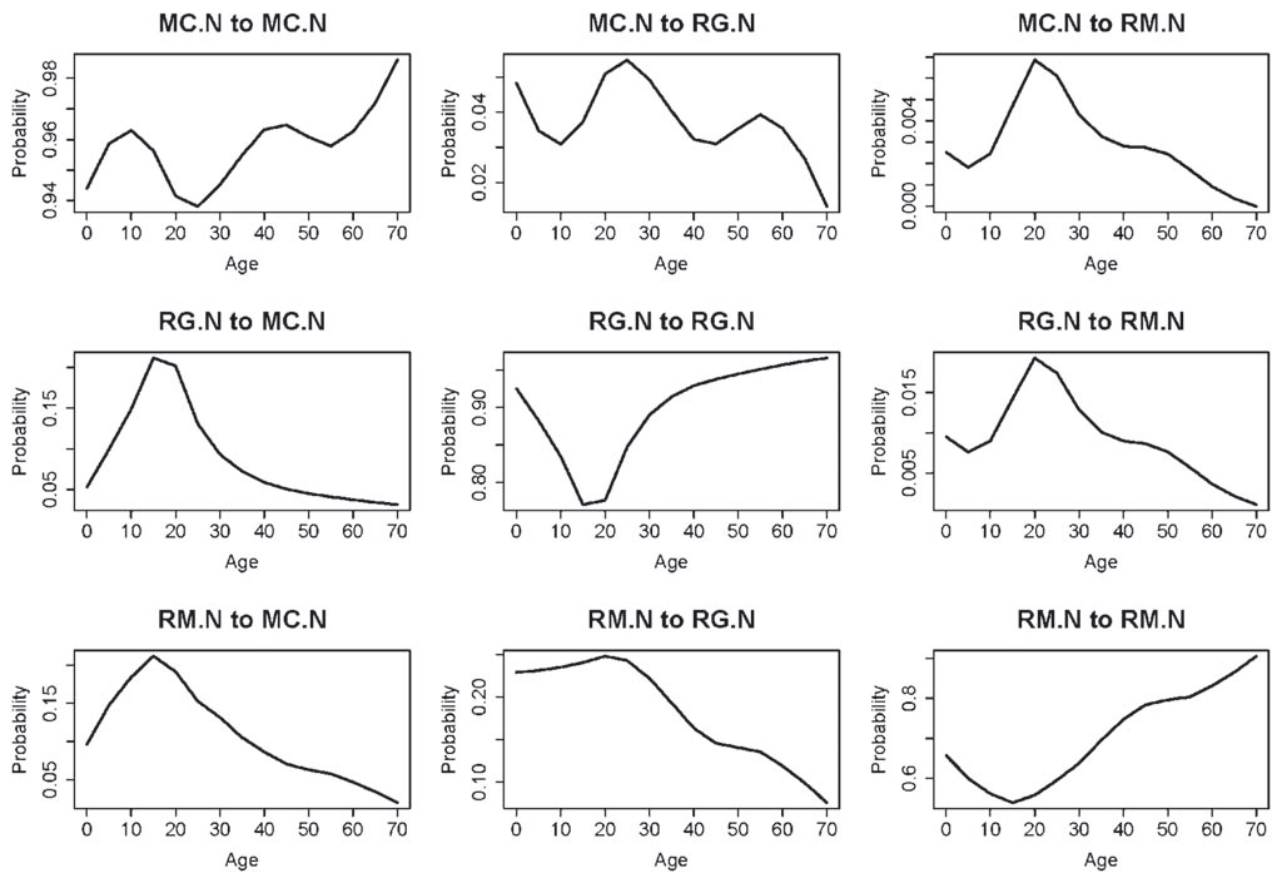

\subsubsection{Area group mortality rates}

Age- and sex-specific mortality rates for the six populations were needed to construct the multistate survival ratios. Using the 2010-12 Indigenous life tables provided by the ABS (2013d), we calculated age- and sex-specific mortality rates at the national level for both the Indigenous and the non-Indigenous populations. The area group life tables were then estimated by proportionating the 2011 age-specific death rates by the age-standardised death rates for major cities, regional areas, and remote areas. For instance, the Indigenous mortality rates in major cities equalled the national rates times 0.798 , which represents the ratio of standardised death rates per 1000 people of major cities to the nation (i.e., 7.9/9.9). The corresponding ratio for the non-Indigenous mortality was 0.965 (i.e., 5.5/5.7).

The log age-specific death rates for females of the six population groups are plotted in Figure 6. The corresponding plots for males appear to be similar to those for females, albeit with somewhat higher rates. The estimated mortality rates for the non-Indigenous population were lower than those of the Indigenous population in all three areas. Moreover, since the mortality rates of Indigenous and non-Indigenous 
Figure 4:

Estimated age-specific probabilities of inter-area group migration for the non-Indigenous population who became Indigenous, 2006-2011
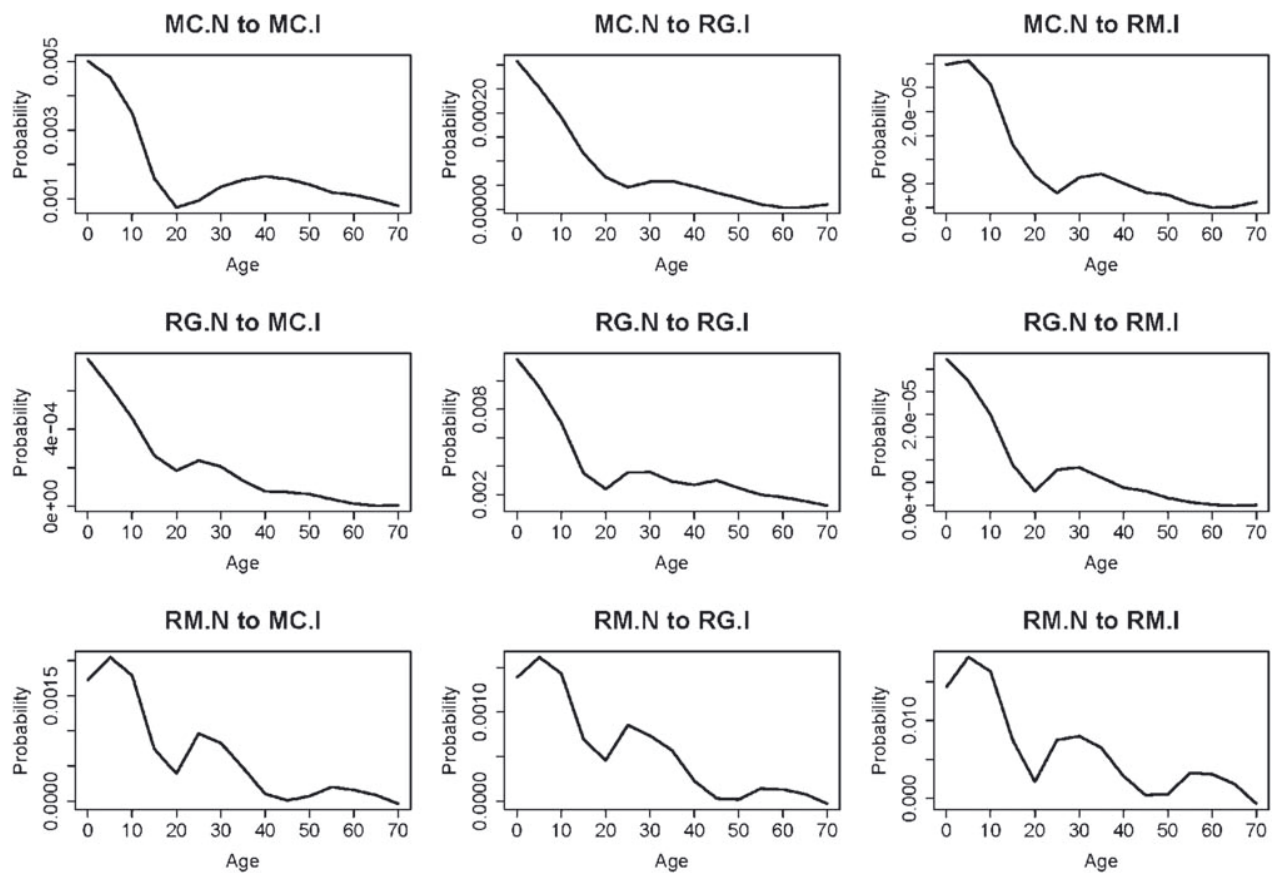

persons in major cities, regional areas, and remote areas were proportioned as described above, they have the same shape, but different magnitudes. Remote areas were estimated to have the highest mortality rates, and major cities were estimated to have the lowest mortality rates.

\subsubsection{Births and fertility rates}

The age-specific fertility rates used in the projection are plotted in Figure 7. The rates reached their maximum at the 20-24 age group for Indigenous women and at the 25-29 age group for non-Indigenous women. Among the six population groups, the maximum rate was exhibited by 20-24-year-old Indigenous women in remote areas. For the non-Indigenous population, the maximum rate was reached in the 2529 age group living in regional areas. It is worth noting that the fertility rates for the mothers aged 40 or older were relatively high for those living in major cities, although the magnitudes were quite small.

As both Indigenous and non-Indigenous women could give birth to Indigenous and non-Indigenous babies, the new births could not be directly projected using 
Figure 5:

Estimated age-specific probabilities of inter-area group migration for the Indigenous population who became non-Indigenous, 2006-2011
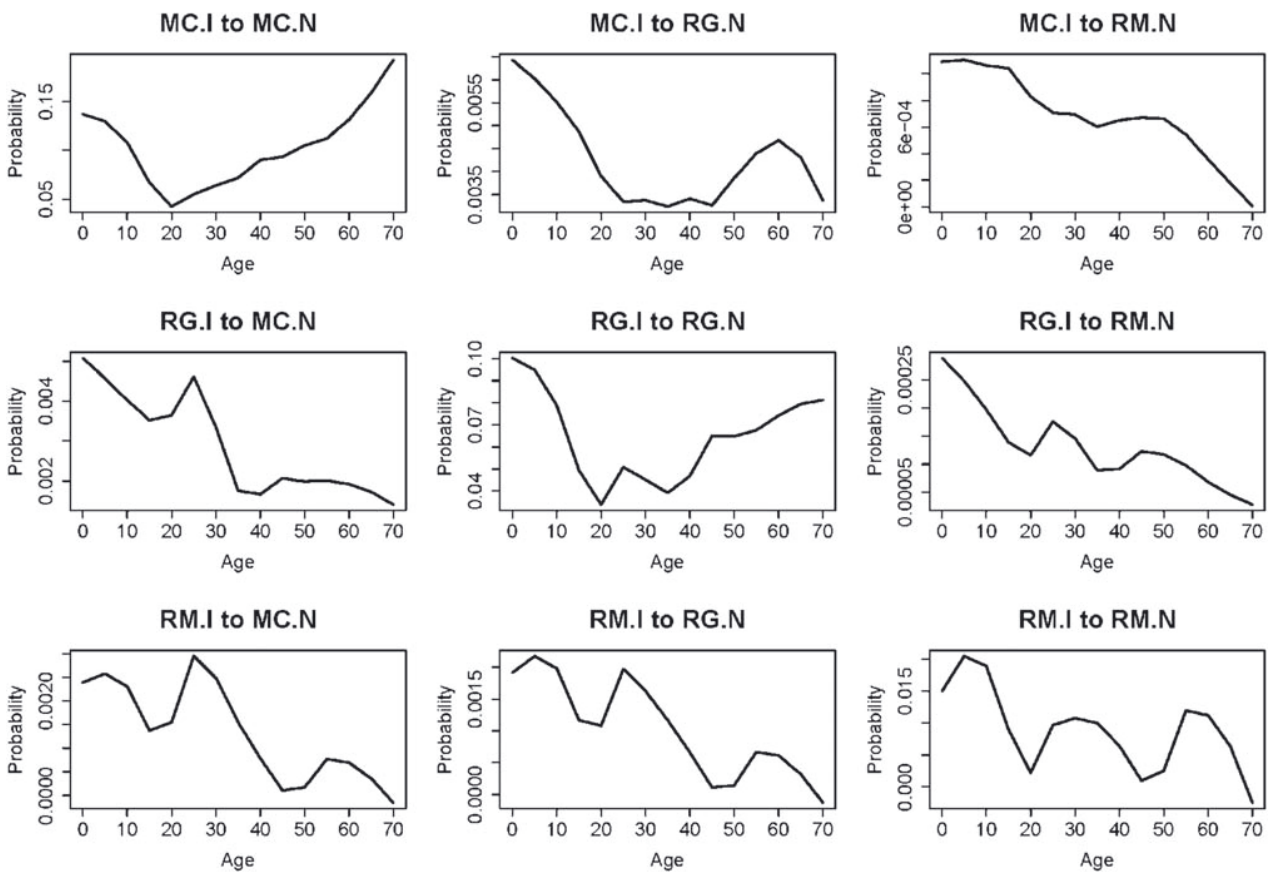

Equation 1. Information was obtained from the ABS to estimate the probabilities of having Indigenous babies by identification status of the women at risk of having births, area group, and age, denoted as $p_{\text {iax }}$. The identification statuses of females and babies were extracted from the 2011 census data, along with the usual residence addresses. To smooth random variations in the observed data, the following logistic regression was used:

$$
\ln \left(p_{\text {iax }} /\left(1-p_{\text {iax }}\right)\right)=I_{i}+O_{a}+A_{x},
$$

where, as before, $I, O$, and $A$ denote identification status, area group of residence, and age (of females), respectively. In addition, we considered all of the three twoway interactions of the three factors, and used the stepwise algorithm based on $\mathrm{AIC}^{5}$ to select the final model.

5 To implement the stepwise algorithm, we start from a full model (with all two-way interactions). At each step, we first do a backward selection by removing a variable so that the lowest AIC is obtained We then do a forward selection by adding back a variable so that the lowest AIC is obtained. We continue this process until no more variables can be removed or added back to obtain a smaller AIC. 
Figure 6:

Female age-specific death rates (log) by identification status and area group, 2011

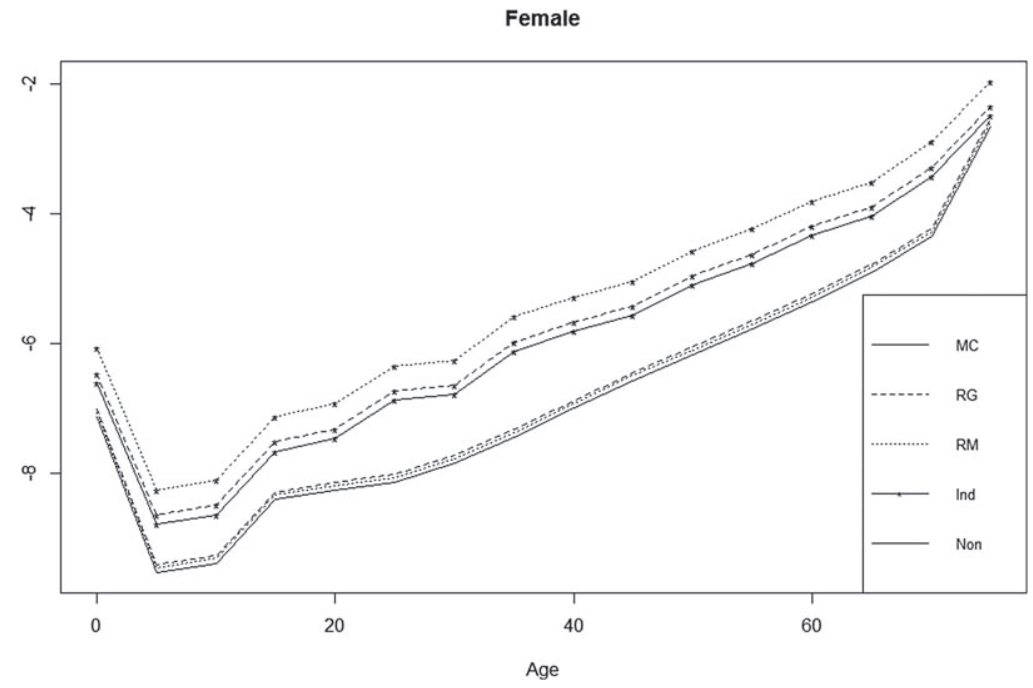

Figure 7:

Age-specific fertility rates per 1000 people by identification status and age group, 2011

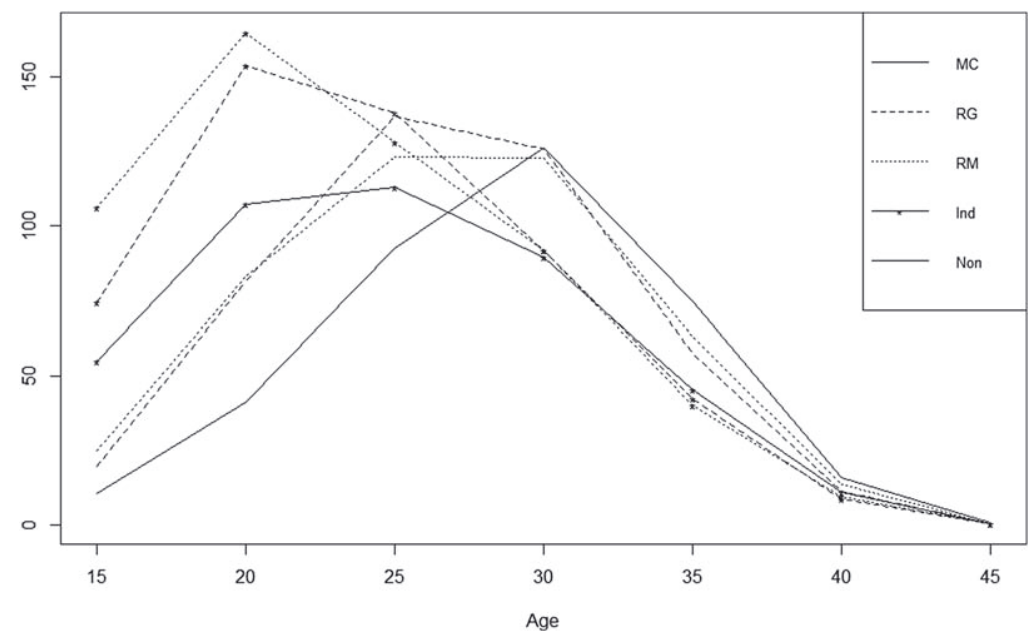

The estimated probabilities of giving birth to Indigenous babies, $\hat{p}_{\text {iax }}$, are tabulated in Table 2. Both Indigenous and non-Indigenous mothers who lived in 
Table 2:

Probabilities of births being Indigenous by identification status and age group of the female population: Major Cities, Regional Areas, and Remote Areas

\begin{tabular}{lccccccc}
\hline & \multicolumn{3}{c}{ Indigenous } & & \multicolumn{3}{c}{ Non-Indigenous } \\
\cline { 2 - 4 } \cline { 6 - 8 } $\begin{array}{l}\text { Age } \\
\text { group }\end{array}$ & $\begin{array}{c}\text { Major } \\
\text { Cities }\end{array}$ & $\begin{array}{c}\text { Regional } \\
\text { Areas }\end{array}$ & $\begin{array}{c}\text { Remote } \\
\text { Areas }\end{array}$ & & $\begin{array}{c}\text { Major } \\
\text { Cities }\end{array}$ & $\begin{array}{c}\text { Regional } \\
\text { Areas }\end{array}$ & $\begin{array}{c}\text { Remote } \\
\text { Areas }\end{array}$ \\
\hline $15-19$ & 1.0000 & 1.0000 & 1.0000 & & 0.0446 & 0.1024 & 0.1515 \\
$20-24$ & 0.9522 & 0.9626 & 1.0000 & & 0.0220 & 0.0520 & 0.0791 \\
$25-29$ & 0.9351 & 0.9489 & 1.0000 & & 0.0116 & 0.0279 & 0.0430 \\
$30-34$ & 0.9369 & 0.9503 & 1.0000 & & 0.0062 & 0.0150 & 0.0233 \\
$35-39$ & 0.9728 & 0.9788 & 1.0000 & & 0.0044 & 0.0107 & 0.0166 \\
$40-44$ & 0.9501 & 0.9609 & 1.0000 & & 0.0063 & 0.0152 & 0.0236 \\
$45-49$ & 1.0000 & 1.0000 & 1.0000 & 0.0162 & 0.0388 & 0.0594 \\
\hline
\end{tabular}

remote areas were more likely to give birth to Indigenous babies. For the nonIndigenous female population, these probabilities were larger for the very young and the oldest reproductive age groups, and were smallest for the 35-39 age group. For Indigenous women, however, no clear differences were found among the age groups.

Finally, for the projection of births, let $K_{0 a 0}$ and $K_{1 a 0}$ denote the number of Indigenous and non-Indigenous births, respectively, by area group $a$. Following Rogers (1995), the projected number of Indigenous births in area group $a\left(K_{1 a 0}\right)$ is equal to $\sum_{x=15}^{x=49}\left[K_{0 a x} B_{0 a x} \hat{p}_{0 a x}+K_{1 a x} B_{1 a x} \hat{p}_{1 a x}\right]$, where in this case $K$ refers to the female population only, $B$ is the fertility rate of this particular female population group, and $x=15-19,20-24, \ldots, 45-49$ years. The projected number of nonIndigenous births $\left(K_{0 a 0}\right)$ is simply $\sum_{x=15}^{x=49}\left[K_{0 a x} B_{0 a x}\left(1-\hat{p}_{0 a x}\right)+K_{1 a x} B_{1 a x}\left(1-\hat{p}_{1 a x}\right)\right]$. For the distribution of these births by sex, we assume the sex ratio at birth is 1.05 (male to female) for all three area groups and both identification statuses. That is, there is a $1.05 /(1+1.05)$ proportion of $K_{0 a 0}$ and $K_{1 a 0}$ being male, and $1 /(1+1.05)$ proportion being female.

\subsubsection{Net international migration totals}

For the projected growth of the non-Indigenous population, net international migration is an important demographic component. Because of the flows between the two populations described above, non-Indigenous projections are also needed as an input for the Indigenous population projections.

In our model, we include age- and sex-specific net international migration as a source of growth for the non-Indigenous population, with the assumption that the levels will continue to increase by 45 percent per five-year interval. This assumption 
is consistent with the growth in net immigration observed between 1981 and 2011. The shares of net international migration in each of the three area groups are assumed to be proportional to the foreign-born populations residing in these areas, as measured in the 2011 census. This assumption is based on the close relationship often found between migrant stocks and migration flows (see, e.g., Bauer et al. (2007)).

Of the approximately 1.2 million people who were overseas five years prior to the 2011 census, only 1377 (or $0.4 \%$ ) identified as Indigenous. This equates to $0.3 \%$ of the total Indigenous population in 2011 (including those aged 0-4). Of the nonIndigenous population, $6 \%$ were overseas five years prior to the 2011 census. Since the proportion was so small for the Indigenous population, we assumed zero net international migration for the Indigenous population projections.

\section{Results}

In this section, our focus is on analysing the transitions between residing in one of the three area groups and identification status, and how these transitions contribute to current and future population change. Multistate population projections based on the 2011 Estimated Resident Populations are also used to identify the relative sources of growth for the Indigenous population in major cities, regional areas, and remote areas for Australia.

\subsection{Area group residence and identification status transitions}

The aggregated smoothed census counts grouped by the usual residence and identification status in $2006(t)$ and in $2011(t+5)$ are presented in Table 3. As the identification statuses are estimated by combining data from the ACLD data and 2011 census, the observations in Table 3 and Table 1 are consistent in the 2011 (column sum) margins with some minor differences (less than 0.01 per cent) due to the smoothing and the application of the estimated age-specific probabilities.

From the two off-diagonal panels of Table 3 , we can see that only 0.27 per cent (i.e., $(23,537+19,935+1980) / 16,828,654)$ of the total non-Indigenous population transitioned to Indigenous status during the 2006-2011 period, compared with 6.80 per cent (i.e., $(14,002+12,725+1243) / 411,596)$ for the Indigenous population. For the Indigenous people who were living in the three area groups and changed their identification to non-Indigenous, the percentages were 10.15 per cent (i.e., $(13,208+644+119) / 137,579)$ for major cities, 7.17 per cent $(619+11,944+$ $30) / 175,673)$ for regional areas, and 1.43 per cent $(175+137+1094) / 98,345)$ for remote areas. The corresponding percentages for the non-Indigenous people transitioning to Indigenous status were 0.20 per cent, 0.42 per cent and 0.77 per cent, respectively. In terms of the population counts, there were 26,245 Indigenous individuals who changed their identification status to non-Indigenous, but stayed in 
Table 3:

Estimated flows of identification status change and migration for area groups in Australia, 2006-2011

\begin{tabular}{|c|c|c|c|c|c|c|c|}
\hline \multirow[b]{3}{*}{ Status 2006} & \multicolumn{6}{|c|}{ Status 2011} & \multirow[b]{3}{*}{ Total } \\
\hline & \multicolumn{3}{|c|}{ Indigenous } & \multicolumn{3}{|c|}{ Non-Indigenous } & \\
\hline & MC & RG & $\mathbf{R M}$ & MC & RG & $\mathbf{R M}$ & \\
\hline \multicolumn{8}{|c|}{ A. Indigenous } \\
\hline $\mathrm{MC}$ & 114,398 & 8,208 & 1,003 & 13,208 & 644 & 119 & 137,579 \\
\hline $\mathrm{RG}$ & 9,816 & 149,526 & 3,736 & 619 & 11,944 & 30 & 175,673 \\
\hline $\mathrm{RM}$ & 1,903 & 7,084 & 87,951 & 175 & 137 & 1,094 & 98,345 \\
\hline Subtotal & 126,117 & 164,818 & 92,690 & 14,002 & 12,725 & 1,243 & 411,596 \\
\hline \multicolumn{8}{|c|}{ B. Non-Indigenous } \\
\hline $\mathrm{MC}$ & 22,354 & 1,000 & 110 & $11,317,286$ & 446,100 & 35,823 & $11,822,673$ \\
\hline $\mathrm{RG}$ & 992 & 18,768 & 39 & 401,510 & $4,256,231$ & 42,322 & $4,719,861$ \\
\hline $\mathrm{RM}$ & 191 & 167 & 1,831 & 31,092 & 53,102 & 199,737 & 286,119 \\
\hline Subtotal & 23,537 & 19,935 & 1,980 & $11,749,887$ & $4,755,433$ & 277,882 & $16,828,654$ \\
\hline Total & 149,654 & 184,753 & 94,670 & $11,763,890$ & $4,768,158$ & 279,125 & $17,240,250$ \\
\hline
\end{tabular}

Note: $\mathrm{MC}=$ Major Cities, $\mathrm{RG}=$ Regional Areas, $\mathrm{RM}=$ Remote Areas

their area group of residence. The number of Indigenous people who changed their identification and moved to a different area group was 1725 , or about 6.2 per cent of this group. For non-Indigenous people, the corresponding numbers were 42,953 who changed their identification but remained, and 2498 (5.5 per cent) who changed their identification and moved.

Both identification change and internal migration contributed to population change in each of the three areas. Major cities gained 9535 Indigenous people through identification change (i.e., 22,354-13,208), and another 2509 people through internal migration (i.e., $9816+1903-8208-1003$ ). Regional areas also experienced net gains in Indigenous population through both identification change $(18,768-11,944=6824$ persons $)$ and internal migration $(8208+7084-9816-$ $3736=1740$ persons). However, the Indigenous population in remote areas declined because of a large negative net internal migration of 4248 people, which was substantially more than the 737 individuals gained through identification change.

As suggested by Figures 2 to 5 , and as shown in previous individual-level modelling (Biddle and Crawford 2015), the interaction between inter-area group migration and identification status change is significant. To further explore this interaction, we present the ratio of the odds of people changing their identification and migrating to the odds of people changing identification (but not migrating) in Table 4. For example, consider the odds ratio of 7.41 for those changing their status from Indigenous and living in remote areas to non-Indigenous and living in major cities. This odds ratio is calculated from the counts presented in Table 3 
Table 4:

Odds ratios of people changing their identification and migrating to people changing their identification and not migrating, 2006-2011

\begin{tabular}{lccc}
\hline & \multicolumn{3}{c}{ Destination } \\
\cline { 2 - 4 } Origin & MC & RG & RM \\
\hline A. Indigenous to non-Indigenous \\
MC & 1.00 & 0.68 & 1.03 \\
RG & 0.79 & 1.00 & 0.10 \\
RM & 7.41 & 1.56 & 1.00 \\
B. Non-Indigenous to Indigenous & \\
MC & 1.00 & 1.13 & \\
RG & 0.56 & 1.00 & 0.21 \\
RM & 0.67 & 0.34 & 1.00 \\
\hline
\end{tabular}

and represents: the ratio of (i) the odds of moving from remote areas to major cities and changing identification to non-Indigenous moving from remote areas to major cities and not changing identification (i.e., $175 / 1903=0.092$ ) to (ii) the odds of changing identification to non-Indigenous to those remaining Indigenous (i.e., $1094 / 87,951=0.012$ ). These types of moves clearly had strong and important effects on identification change.

Table 4 contains very useful information regarding the relationships between migration between different area groups and identification change. Like Indigenous people who were moving from remote areas to major cities, Indigenous people who were moving from remote areas to regional areas were more likely than those who were not moving to change their identification, albeit with a smaller odds ratio of 1.56. However, Indigenous people who were undertaking most of the other kinds of moves retained their status at much higher rates than those who did not move. This was particularly true for Indigenous people who were moving from regional areas to remote areas, for whom the odds ratio was 0.10 .

Among the non-Indigenous population, those who moved from major cities to regional areas and remote areas exhibited odds ratios of 1.13 and 1.55 , respectively; indicating positive relationships between these moves and identification change. The other moves had the opposite effect: i.e., the non-Indigenous people who moved from regional areas and remote areas were much less likely to change their identification to Indigenous. 


\subsection{Projected sources of growth: 2011-2031}

Assuming fixed values for fertility, mortality, and inter-area group migration components, the 2011-2031 projected populations for the three areas and the corresponding sources of growth are presented in Table 5. Comparing the 2011 Estimated Resident Populations and the 2016 projection, we see that the Indigenous population was projected to have increased by 37,730 (16.2 per cent) in major cities, by 40,777 (13.9 per cent) in regional areas, and by 7792 (5.5 per cent) in remote areas. The most important projected source of growth was natural increase (i.e., births - deaths). For major cities and regional areas, the second-most important projected source of growth was net identification change. For remote areas, however, the second-most important source of growth was (negative) net internal migration.

Over two-thirds of the negative net migration of Indigenous persons in remote areas was added to major cities. Identification change contributed positively to Indigenous population growth in all three areas, but especially in major cities. The contributions of people changing both their identification status and their area of residence represented only a small share of the overall population change.

Comparing the projected sources of growth during the 2016-2021, 2021-2026, and 2026-2031 periods, we see that most of the above observations hold, albeit with some noticeable differences. First, levels of natural increase grow steadily over time, from 28,000 to 40,000 for major cities, from 36,000 to 44,000 for regional areas, and from 12,000 to 13,000 for remote areas. Second, levels of net internal migration decrease over time for major cities and remote areas, but increase slightly for regional areas. Third, net identification change to Indigenous status is positive across all three area groups and projection periods, but the levels fluctuate for major cities, decline for regional areas, and increase for remote areas. The net migration and identification changes are relatively small and contribute very little to overall growth, albeit with consistent negative growth for major cities and remote areas and positive growth for regional areas. Overall, we expect Indigenous populations to continue growing in all three area groups in Australia. Between the 2011-2016 and 2026-2031 periods, growth is projected to increase by around 32 per cent for major cities (from 38,000 to 50,000) and remote areas (from 8000 to 10,000). For regional areas, growth is projected to increase by 18 per cent.

\subsection{Multistate population projections}

We now proceed to describe the multistate projections to 2031 holding the 20062011 rates constant. The age-sex compositions of the 2011 Estimated Resident Population (dark shaded bars) and projected 2031 population (diagonal shaded bars) for the Indigenous population are presented for the three areas in Figure 8. There are two conclusions we can draw from these percentage plots and the corresponding plots of population counts (not shown). First, consistent with our observation in Section 4.1, growth is occurring in all area groups and age groups, but particularly 
Table 5:

Sources of Indigenous population change

\begin{tabular}{lrrr}
\hline $\begin{array}{l}\text { Component } \\
\text { of change }\end{array}$ & $\begin{array}{r}\text { Major } \\
\text { cities }\end{array}$ & $\begin{array}{r}\text { Regional } \\
\text { areas }\end{array}$ & $\begin{array}{r}\text { Remote } \\
\text { areas }\end{array}$ \\
\hline 2011-2016 & & & \\
Natural increase & 28,048 & 36,185 & 11,996 \\
Net internal migration & 3,500 & 1,368 & $-4,868$ \\
Net identification change & 6,210 & 2,916 & 743 \\
Net internal migration \& identification change & -28 & 308 & -79 \\
Total & 37,730 & 40,777 & 7,792 \\
2016-2021 & & \\
Natural increase & 30,977 & 38,363 & 12,649 \\
Net internal migration & 3,243 & 1,284 & $-4,527$ \\
Net identification change & 5,669 & 2,003 & 838 \\
Net internal migration \& identification change & -127 & 282 & -90 \\
Total & 39,762 & 41,933 & 8,870 \\
2021-2026 & & \\
Natural increase & 35,533 & 41,639 & 12,786 \\
Net internal migration & 2,697 & 1,464 & $-4,161$ \\
Net identification change & 5,966 & 1,419 & 1,045 \\
Net internal migration \& identification change & -225 & 327 & -96 \\
Total & 43,971 & 44,849 & 9,574 \\
2026-2031 & & & \\
Natural increase & 40,299 & 44,496 & 12,814 \\
Net internal migration & 2,119 & 1,682 & $-3,801$ \\
Net identification change & 7,579 & 1,467 & 1,410 \\
Net internal migration \& identification change & -271 & 407 & -95 \\
Total & 49,725 & 48,052 & 10,328 \\
\hline
\end{tabular}

in major cities and regional areas. Second, ageing is occurring faster in major cities and regional areas, even though the 'pyramid' shape remains more or less the same.

We demonstrated in Section 4.1 that identification change contributes greatly to Indigenous population growth in all three areas. To further verify this point, we compare in Figure 9 three projections of the Indigenous population using our multistate model and a single state model that includes no identification change and fixed net internal migration levels for the years 2011 to 2031. We find that the multistate projection results in larger Indigenous populations in all areas due to the inclusion of identification change. The corresponding ABS projections (not shown) were between the multistate and single state models for major cities, close to the 
Figure 8:

Age-sex composition (percentage) of the Indigenous population: 2011 estimated resident population (grey shade) and 2031 projection (diagonal line)

A. Major Cities

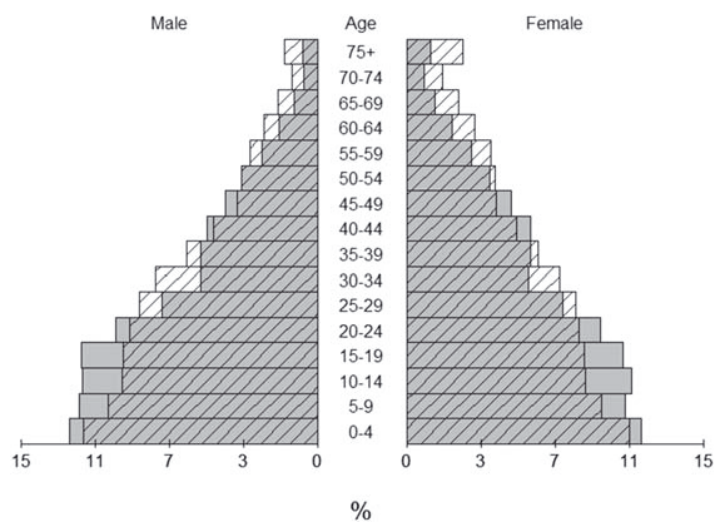

B. Regional Areas
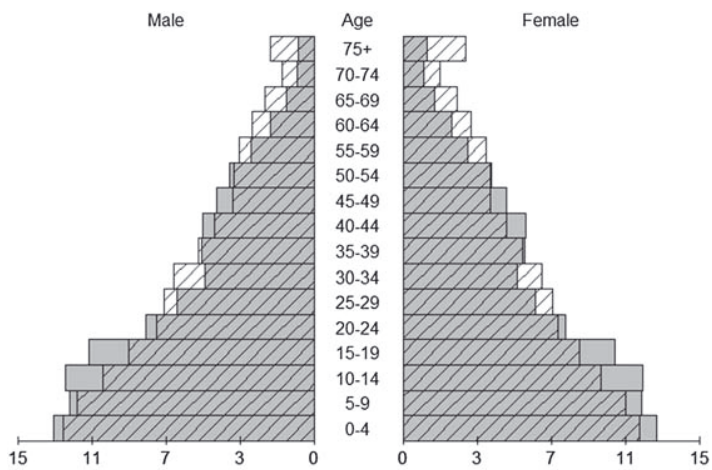

$\%$

C. Remote Areas

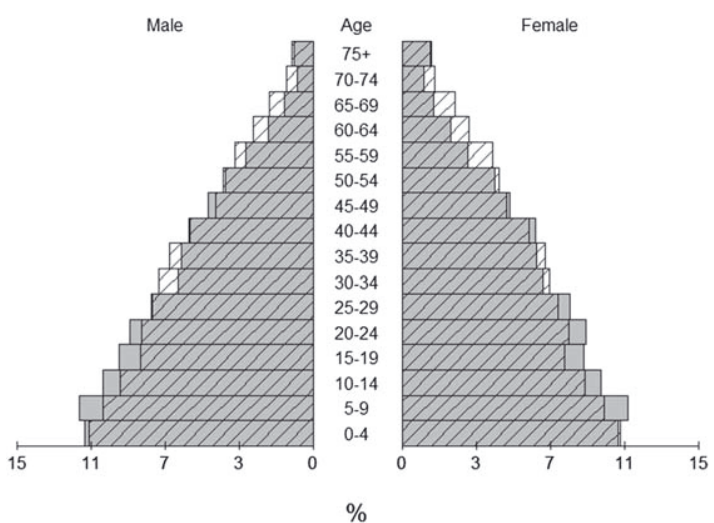


Figure 9:

Multistate and single state Indigenous population projections by area group, 2011 to 2031 (in thousands)

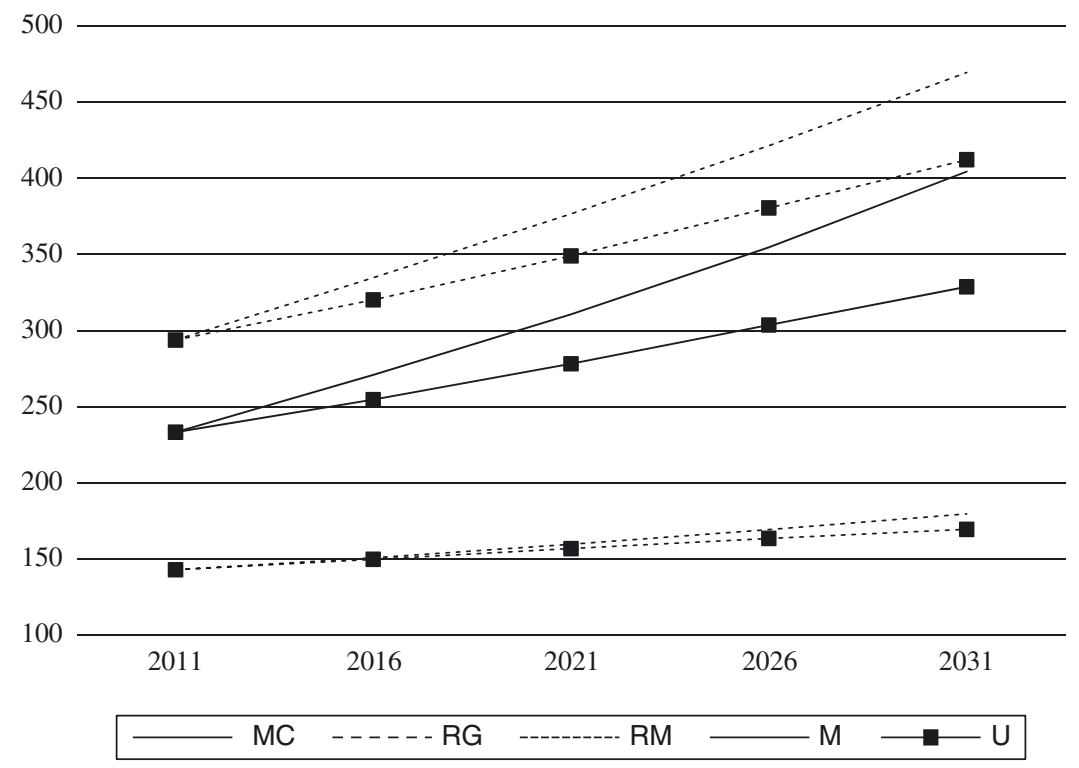

Note: $\mathrm{MC}=$ Major Cities, $\mathrm{RG}=$ Regional Areas, $\mathrm{RM}=$ Remote Areas, $\mathrm{M}=$ multistate, $\mathrm{U}=$ single state

multistate model for regional areas, and below the single state projection for remote areas.

\section{Conclusion}

The Australian Aboriginal and Torres Islander (Indigenous) peoples are socially identified. Unlike in some other comparable countries, there are no widespread registries of the Indigenous population in Australia, which means that many people living Australia can and do change their identification at different points in time. This identification change is driven by a number of factors, including social conditions, life course events, and the context in which the identification takes place.

In this paper, we explored the relationships between internal migration and identification change among the Indigenous population in Australia. Our analysis involved combining and smoothing data from the 2011 census and the Australian Census Longitudinal Dataset and developing a multistate population projection model that included births, deaths, internal migration, and identification change. We showed that even though natural population increase made up the greatest component of net population change, identification change was an important 
additional contributor to the growth in the Indigenous population. The interaction between identification change and internal migration also led to a small but important projected spatial realignment of the population, predominantly from more to less remote parts of the country. These results provide important insights into the forces that are driving Indigenous population change in Australia.

By taking advantage of these additional data, and of our improved access to the existing data, we were able to gain a richer understanding of Indigenous population change. Having access to unit-record ACLD data would allow us to develop an even richer model of identification change that could include an interaction between the structural geography used in this paper and administrative boundaries. When results from the 2016 census are linked to the 2006-2011 ACLD (creating three waves of data), we will be able to obtain more stable estimates of identification changes and their relationship with population mobility. Moreover, having access to this expanded linked dataset will enable researchers to investigate whether people who change their identification over one intercensal period have a higher (or lower) probability of changing their status over the subsequent period.

There are other demographic processes that could be analysed alongside identification change. By linking data from the ACLD to births or deaths registries, it would be possible to test whether the newly identified population is subject to other demographic processes that are more akin to those of the rest of the Indigenous population or the rest of the non-Indigenous population.

The model could be extended by identifying two separate non-Indigenous populations. The first population, defined as those at relatively high risk of identification change, would include individuals listed in the census who were born in Australia and had at least one parent born in Australia. The second population, defined as those at relatively low risk of identification change, would include individuals listed in the census who were born overseas, had two parents who were born overseas, or were added to the population through projected international migration beyond the base year. Distinguishing between these two populations in both the calculation and the application of rates of identification change would likely improve the accuracy of projections of future population change.

While extensions of the model and the use of new data sources are possible, we have shown in this paper that careful analysis of identification change and its interactions with internal migration has the potential to increase our understanding of future Indigenous population developments, and to enable both government and community organisations to adopt more effective and forward-looking approaches to policy design.

\section{Acknowledgements}

This paper was prepared for presentation at the Australian Population Association Conference, Sydney, 29 November-2 December 2016; and the 'Variations on the themes of Wolfgang Lutz' Wittgenstein centre Conference, Vienna, 5-7 December 
2016. This research was funded by the Australian Research Council as part of the Linkage Project on 'Improved Indigenous population projections for policy and planning' (LP130100735).

\section{References}

ABS 1971. Census of population and housing, 1971. Catalogue No. 2105.0, Australian Bureau of Statistics, Canberra. Available at: http://www.abs.gov.au/ausstats/abs@.nsf/mf/ 2105.0 [Accessed 24 October 2016].

ABS 2004. Experimental estimates and projections, Aboriginal and Torres Strait Islander Australians, 1991 to 2009. Catalogue No. 3238.0, Australian Bureau of Statistics, Canberra. Available at: http://www.abs.gov.au/AUSSTATS/abs@.nsf/Lookup/ 3238.0Main+Features11991\%20to\%202009 [Accessed 16 October 2016].

ABS 2009. Experimental estimates and projections, Aboriginal and Torres Strait Islander Australians, 1991 to 2021. Catalogue No. 3238.0, Australian Bureau of Statistics, Canberra. Available at: http://www.abs.gov.au/AUSSTATS/abs@.nsf/Lookup/ 3238.0Main+Features11991\%20to\%202021?OpenDocument [Accessed 16 October 2016].

ABS 2012. Census of population and housing: Counts of Aboriginal and Torres Strait Islander Australians, 2011. Catalogue No. 2075.0, Australian Bureau of Statistics, Canberra. Available at: http://www.abs.gov.au/ausstats/abs@.nsf/mf/2075.0 [Accessed 24 July 2016].

ABS 2013a. Australian Statistical Geography Standard (ASGS): Volume 5 - Remoteness structure. Catalogue No. 1270.0.55.005, Australian Bureau of Statistics, Canberra. Available at: http://www.abs.gov.au/ausstats/abs@.nsf/mf/1270.0.55.005 [Accessed 25 October 2016].

ABS 2013b. Census of population and housing: Understanding the increase in Aboriginal and Torres Strait Islander counts, 2006-2011. Catalogue No. 2077.0, Australian Bureau of Statistics, Canberra. Available at: http://www.abs.gov.au/ausstats/abs@.nsf/mf/2077.0 [Accessed 24 March 2015].

ABS 2013c. Australian Census Longitudinal Dataset: Methodology and quality assessment, 2006-2011. Information Paper 2080.5, Australian Bureau of Statistics, Canberra.

ABS 2013d. Life tables for Aboriginal and Torres Strait Islander Australians, 20102012. Catalogue No. 3302.0.55.003, Australian Bureau of Statistics, Canberra. Available at: http://www.abs.gov.au/ausstats/abs@.nsf/mf/3302.0.55.003 [Accessed 24 July 2016].

ABS 2014a. Australian historical population statistics, 2014. Catalogue No. 3105.0.65.001, Australian Bureau of Statistics, Canberra. Available at: http://www.abs.gov.au/ausstats/ abs@.nsf/mf/3105.0.65.001 [Accessed 2 August 2016].

ABS 2014b. Estimates and projections, Aboriginal and Torres Strait Islander Australians, 2001 to 2026. Catalogue No. 3238.0, Australian Bureau of Statistics, Canberra. Available at: http://www.abs.gov.au/ausstats/abs@.nsf/mf/3238.0 [Accessed 2 July 2016].

ABS 2015. Births, Australia, 2013. Catalogue No. 3301.0, Australian Bureau of Statistics, Canberra. Available at: http://www.abs.gov.au/ausstats/abs@.nsf/mf/3301.0 [Accessed 4 July 2016]. 
Bauer T., G. S. Epstein and I. N. Gang 2007. The influence of stocks and flows on migrants' location choices. Aspects of Worker Well-Being 26: 199-229.

Biddle N. 2013. Population projections. 2011 Census Papers 14/2013, CAEPR Indigenous Population Project. Centre for Aboriginal Economic Policy Research, Research School of Social Sciences, Australian National University, Canberra.

Biddle N. 2014. Determinants of wellbeing for Indigenous Australians. Catalogue No. IHW 137. Australian Institute for Health and Welfare, Canberra.

Biddle N. and H. Crawford 2015. The changing Aboriginal and Torres Strait Islander population: Evidence from the 2006-11 Australian Census Longitudinal Dataset. CAEPR Indigenous Population Project 2011 Census Paper 18, Centre for Aboriginal Economic Policy Research, Research School of Social Sciences, Australian National University.

Biddle, N. and K. Johnstone 2014. Indigenous family formation. In Family Formation in 21st Century Australia, eds G. Heard and D. Arunachalam. New York: Springer.

Biddle, N. and J. Taylor 2009. Indigenous population projections, 2006-31: Planning For Growth. CAEPR Working Paper 56/2009, Centre for Aboriginal Economic Policy Research, Research School of Social Sciences, Canberra: Australian National University.

Biddle, N. and T. Wilson 2013. Indigenous Australian population projections: Problems and prospects. Journal of Population Research 30(2): 101-116.

Biddle, N., M. Howlett, B. Hunter and Y. Paradies 2013. Labour market and other discrimination facing Indigenous Australians. Australian Journal of Labour Economics 16(1): 91-113.

Biddle, N., S.-E. Khoo and J. Taylor 2015. Indigenous Australia, White Australia, Multicultural Australia: The demography of race and ethnicity in Australia. In The international handbook of the demography of race and ethnicity, Volume 4, eds R. Saenz, D. G. Embrick and N. P. Rodríguez, 599-622. Dordrecht: Springer.

Gray, A. 1997. The explosion of aboriginality: Components of indigenous population growth 1991-96. Discussion Paper 142/1997, Centre for Aboriginal Economic Policy Research, The Australian National University, Canberra.

Gray, A. and K. Gaminiratne 1993. Indicative projections of the Aboriginal and Torres Strait Islander population to 2011. CAEPR Discussion Paper 52/1993, Centre for Aboriginal Economic Policy Research, Research School of Social Sciences, Australian National University, Canberra.

Khalidi, N. A. 2008. Indicative New South Wales Indigenous population projections 2006 to 2021. NSW Aboriginal Housing Office, Sydney. Available at: https://www.parliament.nsw.gov.au/committees/DBAssets/InquiryOther/Transcript/ 7619/Q3\%20Attach\%208\%20Indigenous\%20Population\%20Projections.pdf [Accessed 31 October 2018].

Kinfu, Y. and J. Taylor 2005. On the components of Indigenous population change. Australian Geographer 36(2): 233-255.

Land, K. C. and A. Rogers (eds) 1982. Multidimensional Mathematical Demography. New York: Academic Press.

Malaspinas, A. S., M. C. Westaway, C. Muller and et al. 2016. A genomic history of Aboriginal Australia. Nature 538(13 October 2016): 207-214. 
O'Donnell, J. and J. Raymer 2015. Identification change and its effect on projections of the Aboriginal and Torres Strait Islander population in Australia. Journal of Population Research 32(3-4): 297-319.

O'Reilly, J. B. 1994. Demographic implications of Aboriginal out-marriage. Journal of the Australian Population Association 11(2): 149-157.

Raymer, J., N. Biddle and P. Campbell 2017. Analysing and projecting Indigenous migration in Australia. Applied Spatial Analysis and Policy 10(2): 211-232.

Rogers, A. 1975. Introduction to multiregional mathematical demography. New York: John Wiley and Sons.

Rogers, A. 1990. Requiem for the net migrant. Geographical Analysis 22: 283-300.

Rogers, A. 1995. Multiregional demography: Principles, methods and extensions. Chichester: Wiley.

Rogers, A. 2015. Applied multiregional demography: Migration and population redistribution. Dordrecht: Springer.

Rogers, A., J. Little and J. Raymer 2010. The indirect estimation of migration: Methods for dealing with irregular, inadequate, and missing data. Dordrecht: Springer.

Ross, K. 1996. Population issues, Indigenous Australians. ABS Occasional Paper, Catalogue No. 4708.0, Australian Bureau of Statistics, Canberra.

Schoen, R. 1988. Modeling Multigroup Populations. New York, USA: Plenum Press.

Steering Committee for the Review of Government Service Provision (2015) Report on Government Services 2015: Indigenous Compendium. Productivity Commission, Canberra.

Taylor, J. 1997. The contemporary demography of Indigenous Australians. Journal of the Australian Population Association 14(1): 77-114.

Taylor, J. 2003. Indigenous Australians: The first transformation. In The transformation of Australia's population: 1970-2030, eds S.-E. Khoo and P. McDonald, 17-39. Sydney: University of New South Wales Press.

Wilson, T. 2009. A multistate model for projecting regional populations by Indigenous status: an application to the Northern Territory, Australia. Environment and Planning A 41(1): 230249.

Wilson, T. 2014. New population and life expectancy estimates for the Indigenous population of Australia's Northern Territory, 1966-2011. PLoS ONE 9(5):e97576. DOI: 10.1371/journal.pone.0097576. 